\title{
Library on the Go: A Focus Group Study of the Mobile Web and the Academic Library
}

\author{
Jamie Seeholzer and Joseph A. Salem, Jr.
}

This study explores student use of the mobile Web in general and expectations for an academic library's mobile Web site in particular through focus groups with students at Kent State University. Participants expressed more interest in using their mobile Web device to interact with library resources and services than anticipated. Results showed an interest in using research databases, the library catalog, and reference services on the mobile Web as well as contacting and being contacted by the library using text messaging.

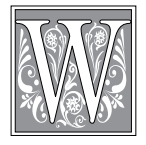

hile exploring his new iPhone, a Web developer at Kent State University Libraries was curious to see if Kent State had a mobile version of its Web site. He was surprised to see the library listed as one of the top ten links on the university's mobile Web homepage. Clicking on the library link brought him to a seemingly random list of links from the libraries' Web site, some of which connected to nothing. As a result, the libraries' Web Point Committee decided to develop a site for mobile device users. Following well-established practice at Kent State, the first step was to gather user feedback.

As members of the Web Point Committee, we were charged with gathering feedback from Kent State students about their use and perceptions of the mobile Web. We decided to use focus groups to gather user feedback, as we have used them before and we were particularly interested in the perceptions of students about using the mobile Web. We had already been cautioned by our Web developers that it would not be feasible to duplicate our entire Web site for a mobile device. With this information in mind, we were interested in learning from students which features of our traditional Web site would be most useful on a mobile device. Our final objectives for this project were to determine approximately how much time our students were using the Web on their mobile devices, which features of the library they could envision themselves using on these devices, and other services they would be interested in having. We wanted to replace the library content on the university's mobile Web site.

\section{Literature Review}

The mobile Web is "the World Wide Web accessed through a mobile device, ranging from a cellular phone to an iPod

Jamie Seeholzer is First Year Experience Librarian, Reference and Instruction, at Kent State University; e-mail: jseeholz@kent.edu. Joseph A. Salem, Jr. is Head, Reference and Government Information Services, Kent State University; e-mail: jsalem@kent.edu. (C) Jamie Seeholzer and Joseph A. Salem, Jr. 


\begin{tabular}{|c|c|}
\hline $\begin{array}{c}\text { FIGURE } 1 \\
\text { Kent State University Mobile Site }\end{array}$ & \\
\hline KENT STATE & \\
\hline \multirow[t]{2}{*}{\begin{tabular}{|l} 
Admissions \\
Dining and Menus \\
Directions and Maps \\
Kent State Campuses \\
Libraries and Media Services \\
Majos and Degees \\
News and Advisories \\
Online Directory \\
Search \\
Sports \\
\end{tabular}} & \\
\hline & $\begin{array}{l}\text { Powered by Usablenet } \\
\text { Help/Feedback }\end{array}$ \\
\hline
\end{tabular}

Touch." 1 The use of the mobile Web has been on the rise since most cellular phones as well as some MP3 players and PDAs have greater Web functionality and run on faster (3G) networks with greater connectivity. ${ }^{2}$ The use of the mobile Web has increased in the past few years, with a recent Internet poll reporting 39 percent of Americans using their mobile devices to access the Internet ${ }^{3}$ or about 40 million active users from demographically diverse backgrounds. ${ }^{4}$ This increase in use shows that "mobile connectivity is the new centerpiece of high-tech life." ${ }^{5}$

For academic libraries, the mobile Web appears to be a new area for outreach. The importance of the mobile Web for libraries was first forecasted in 2000 by Michael O'Leary. ${ }^{6}$ Librarians have already incorporated and planned for the use of mobile devices in their libraries. Librarians are already using the mobile Web to deliver library instruction, access book and audiobook collections, conduct audio tours, send out text message notifications, and provide reference assistance. ${ }^{7}$ In addition to these high-tech applications, many libraries have created mobile versions of their traditional Web sites. ${ }^{8}$

Although some librarians reported about their initiatives and plans for library resources on mobile Web devices, a review of the literature reveals no published studies about the use of the mobile Web by library patrons. Librarians have been very active in creating blogs, wikis, and presentations about the possibilities of the mobile Web for libraries, but these items do not appear to touch on how to create these technologies or what works, but instead reports on what others have done. ${ }^{9}$ Librarians in the United Kingdom have taken a lead in incorporating findings from surveys about mobile use into library applications. ${ }^{10}$ Broader studies have been conducted about the use of the mobile Web in general and user expectations for Web sites on mobile devices. ${ }^{11}$ Articles in the library literature that discuss the mobile Web urge librarians to develop a thorough understanding of their users that will guide the creation of, and the content for, a mobile Web site. ${ }^{12}$ Lippincott echoes the importance of knowing the audience for a mobile Web site and suggests focus groups as a way to assess the needs of a local population..$^{13}$ Although there are numerous examples of the use of mobile devices for library resources, the literature does not contain any discussion of how librarians created these sites and services or why they felt the need to. Some authors suggest librarians "defin[e] what amount and what type of information is appropriate" for a mobile Web site, but not how to go about making those definitions. ${ }^{14}$ In addition to the formal literature, current examples of library Web sites for mobile devices were reviewed; prominent examples included the sites from Harvard, Duke, Ohio State and Texas Christian University. 
These sites all favored a simplistic style and chose to highlight links about hours and availability of services.

\section{Methodology}

For the current study, we were interested in the use, expectations, and perceptions of the mobile Web by Kent State students. Because we were mostly interested in qualitative data and Kent State students are inundated with university surveys seeking their opinions, we decided to use focus groups to gather feedback. To accomplish this from our biggest user group, we limited the first round of focus groups to Kent State students. Future research could include focus groups with faculty, staff, and unique populations such as distance learners. Eleven question prompts were prepared in three broad categories to guide discussion in the focus groups. The prompts evolved slightly from the pilot session to the datagathering sessions. The version shared below reflects their final state. The first six prompts asked questions focused on personal experiences with mobile Web devices, the devices that students use, and their use of mobile Web sites.

1. Do you currently have the ability to view Web sites from a mobile device? What kind of device do you use?

2. Which sites specifically are you using? How often do you visit them?

3. Why do you go to these sites? How do you use them?

4. What capabilities do you currently have for viewing mobile versions of Web sites?

5. What capabilities would you like to have?

6. What works in mobile Web versions? What doesn't?

The next four prompts explored library use of the mobile Web by students and their receptivity to mobile Web versions of library resources.

7. Do you see a need for libraries to have Web sites for mobile devices?
Why would you use the library on your mobile device?

8. From the library's Web site, what features do you think you would be most likely to use on your mobile device?

9. Would you be interested in a mobile version of the library catalog?

10. Do you have any ideas for tools that you would like to see the library develop for mobile devices?

The last prompt sought feedback on other technologies the library could use to reach users.

11. What other technologies would you be interested in using? For example, texting the reference desk for help, sending information from library resources to your phone (such as call numbers or database results).

\section{Participants and Focus Group Sessions}

Undergraduate and graduate students were recruited for this study through online advertising, flyers distributed on campus, and by word of mouth. Participants were compensated for their time (\$10 was credited to their campus debit card accounts) and provided with lunch. The sessions were conducted in the Main Library. The location and advertising methods may have been skewed to participants who were library users.

Four focus groups were conducted during the spring semester of 2009. The goal for each session was a participant group of between five and nine. The first session was used as a pilot session to make sure that each of the eleven prompts could be covered while allowing extra time for the conversation to develop and to get the mechanics of the focus group sessions established. We decided to pass around an iPod Touch so students could see how some resources would appear on a mobile device. We used this first pilot session to decide how the device would be passed around, the pacing of the questions, and to investigate any other ques- 
tions we wanted to add to the discussion prompts. We did not add or eliminate any questions from our discussion guide following this practice session; we made only slight revisions to the original question prompts.

Each focus group session was held in a conference room in the Main Library. The room is removed from the busier sections of the library and provides comfortable seating around a large conference table. A computer with a projector was used to display the library's traditional Web site as well as mobile versions of other library Web sites. An iPod Touch with Internet access was passed around so participants could get an idea of scale on a small screen and look at features. Each focus group session was recorded and transcribed.

To facilitate conversation, we attempted to maintain a relaxed, informal tone and attitude during the focus group sessions. As participants entered the conference room, they were encouraged to begin eating the provided lunch and to read over and sign a consent form. We then introduced ourselves and explained the purpose for the focus group. Participants were asked if they had any questions or concerns before the recorder was turned on and discussion began. No students declined to participate after the start of the focus group sessions.

A significant benefit of the focus group format is its ability to gather exploratory data, particularly through the conversation and dynamics of each focus group session. We attempted to strike a balance between facilitating rich and exploratory discussion and gathering valid and reliable data by ensuring consistency across the three data-gathering sessions. Consistency was ensured by following the same schedule for each session. Each session began with the same introduction. Each participant was then asked to read his or her number into the recorder to help with transcription. Before the discussion began in each session, participants were given the opportunity to ask questions about the session itself. Once the session discussion began, the same prompts were used in the same order for all three sessions. Although some follow-up questions by the facilitator or by other participants were unique to each session, the discussions were found to be consistent when the sessions were transcribed and reviewed. Furthermore, the responses to the eleven prompts and the data gathered regarding the elements of the current Web site that participants wanted to see incorporated on the mobile Web site were also consistent across the three sessions.

This study is based on responses gathered from 20 students over three focus group sessions held in March and April of 2009. The participants were a mix of undergraduate and graduate students and covered a variety of ages including traditional and nontraditional students.

\section{Findings and Discussion Focus Group Results}

Each of the transcripts was analyzed for the responses to each of the eleven prompts and for themes that consistently emerged across the sessions. In most cases, we concluded the discussion prompted by each question with a "sense of the group" summary, which allowed the content analysis of the discussion prompts to focus more on differences among the groups and not among individuals within the groups. As you will see, the data gathered were consistent across the three sessions. In addition to analyzing the responses to the discussion prompts, the transcripts were analyzed for any themes that consistently emerged across the three sessions. As themes were noted in one session, any examples in the other sessions were noted as well. Themes are reported below when they were evident in the transcripts for at least two of the three sessions and, in most cases, for all three.

For the sake of brevity, the data gathered in response to the eleven discussion prompts are not discussed individually, but within the three topic areas explored through the discussion guide: 1 ) use and perception of the mobile Web by KSU 
students; 2) library resources for the mobile Web; and 3) other technologies for the library to explore. The themes that emerged in the data are discussed as well.

\section{Use of the Mobile Web by KSU Students}

Most of the participants in the focus groups had Web access on their mobile device, and those who did not have such access expressed interest in obtaining a mobile device with Web connectivity. Participants varied in how often they use their mobile Web access, if they had it, with some estimating they used it almost daily and others citing infrequent use due to the cost of accessing the Web with their existing phone contract. Participants who were using their mobile Web access frequently cited a few common Web sites (Facebook, e-mail, weather, directions, and sports sites) as places they often visited on their mobile device.

Participants were asked to estimate how much time they could anticipate using library resources on their mobile devices. Most participants felt they would use library resources on their mobile devices, especially to begin a research project:

Let's say if we get an assignment, if I'm in a car or something, I would definitely search stuff and maybe find the websites and save them, that way I could later go back to them then, because I'm not doing anything, I mean, you could at least find the websites. I think that's what I would definitely do, would use it just to get the initial stuff and maybe go to my laptop later and work on it. $(4 / 20 / 2009)$

If it occurs to me that I need to look for something in particular and I'm not near my computer, I could find the links and e-mail them to myself so I could go and find them again later. $(4 / 20 / 2009)$

A few saw no need to use their mobile devices for research:
I probably wouldn't really use it much, I mean, maybe if I'm walking from my house to the library or something but for something quick, I don't really see myself doing any research on my phone. I would just use my laptop or a computer on campus for all this stuff. (4/20/2009)

\section{Library Resources for the Mobile Web}

A significant amount of time was spent during the focus groups discussing the Kent State University Libraries' traditional Web site and the links contained on its homepage. As addressed above, the second section of question prompts dealt with the particular library resources participants could see themselves using on their mobile devices.

The Kent State University Libraries Web site features three groupings of links: Research, Services, and About Us. Each cluster features a set of links that serve as way finders on the Libraries' Web site. Among other links, the Research section features links to the libraries' research databases, subject guides pertaining to majors taught on the Kent campus, and a Journal Finder that determines the holdings of a particular journal title either in print or online. The Services section features information about Interlibrary Loan, off-campus access to resources, tutoring services, My Library Account (for renewing books and materials) and multimedia help. Finally, the About Us section features a building guide, a listing of the library's hours and service points, as well as locations and directions to the fourteen libraries that comprise the Kent State University Libraries system.

To ascertain which links students would find most useful from each section, we gave each participant a handout listing the links on each of these pages and asked them to circle the links they could see themselves using on a mobile device. We also asked the participants to rank which section (research, services, about us) would be the most useful to them on a mobile device. A discussion of our 
findings for each section of the University Libraries' Web site follows.

\section{Research}

The Research section of the Libraries' Web site provides links to research databases, subject guides, style manuals, and our Journal Finder. Surprisingly, a number of participants identified research databases as an essential element of a mobile version of the Libraries' Web site. Even after participants were informed that research databases would most likely not be formatted for mobile devices, they still expressed interest in having these tools available from the library's mobile site. Most participants were eager to have the research databases available on their mobile devices, primarily for beginning their research.

If I want to know do they have that, just a really quick lookup in the catalog or the journal finder. In a database, I wouldn't do extensive playing around with the source. (4/8/2009)
The convenience of having access to research databases on something as portable as a mobile device was also mentioned.

I think it is convenient because maybe if you're in class and you need to look quickly or even if you're on the go I think all the information in a smaller would be more helpful. But at the same time, if you're in intense research you probably want a kind of more comfortable access...so it kind of depends on the situation. $(3 / 4 / 2009)$

I would be willing to do actual research on a phone, like an iPhone just because it's smaller than my laptop so I wouldn't have to lug my laptop to campus. (3/4/2009)

When asked how they would use the research databases, participants said they would be interested in reviewing

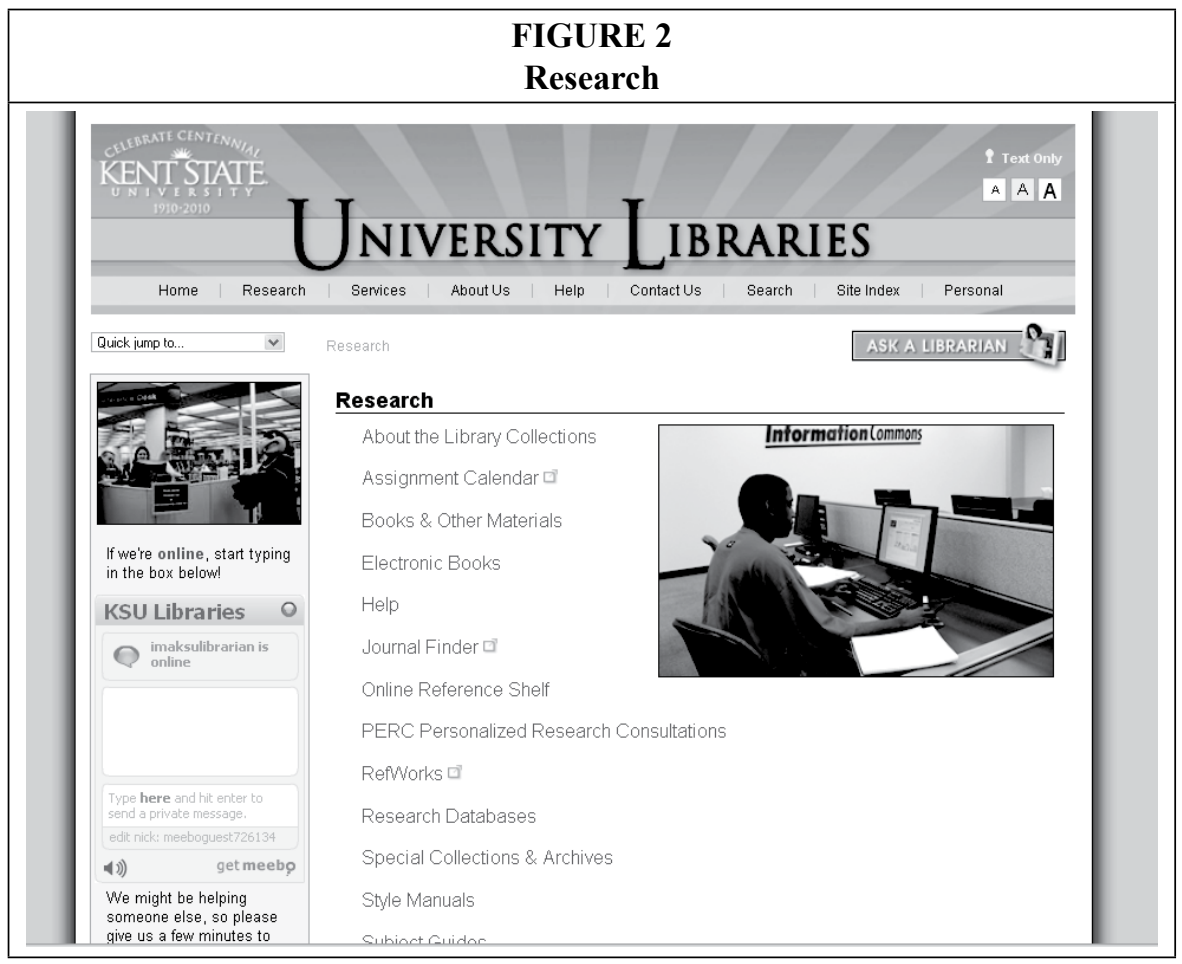




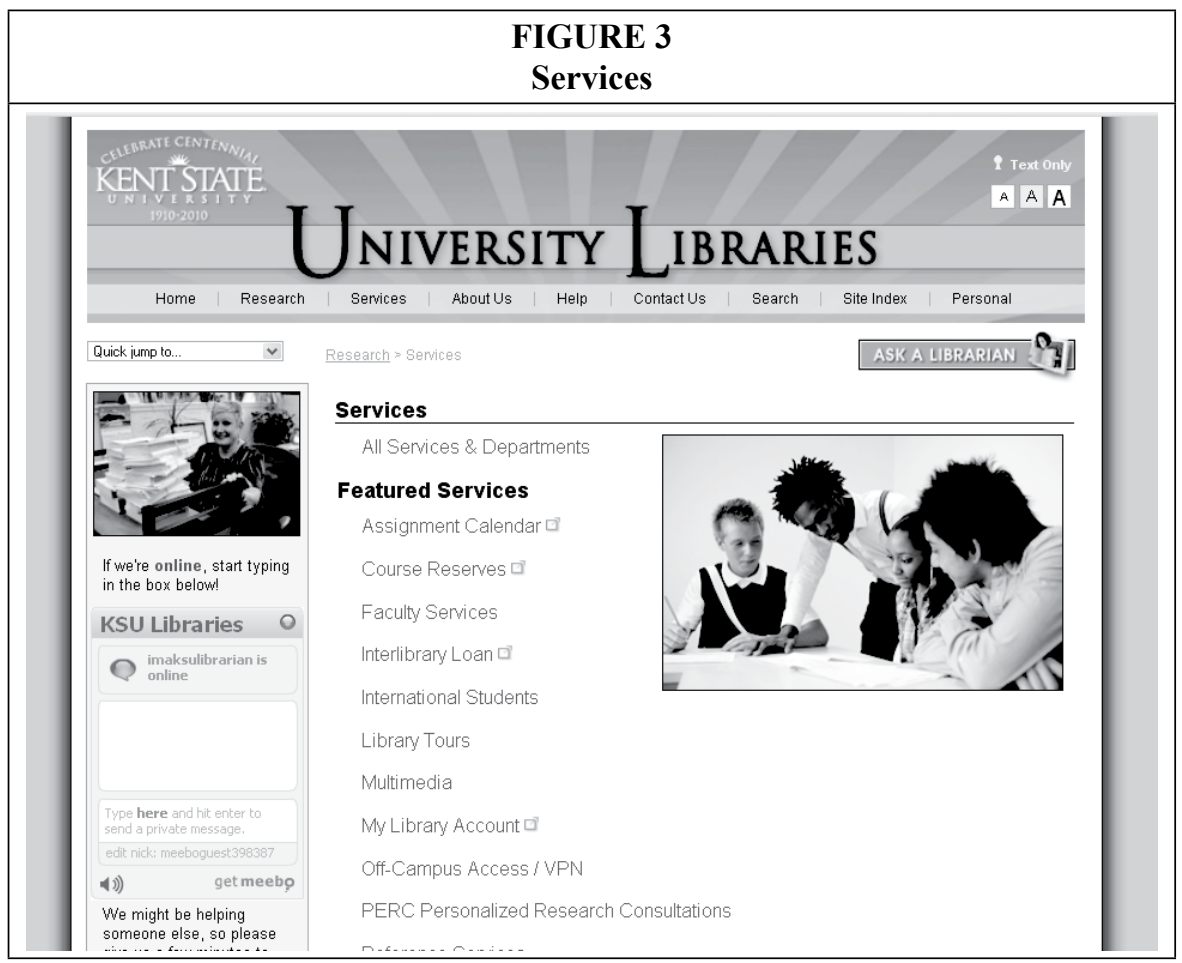

the available literature on a topic, perhaps not reading the entire document on their mobile device, but beginning their research at least:

I would not read the whole articles in the mobile device, but search. $(3 / 4 / 2009)$

Especially if I were standing in line somewhere and waiting, I would absolutely start doing research for something and then save my citations. $(4 / 8 / 2009)$

Participants suggested not including nearly 200 of the University Libraries' databases on a mobile version of the Web site but instead selecting a few major resources, such as EBSCO's Academic Search Complete or the OhioLINK Electronic Journal Center, and providing a link to the rest of the library's databases on an alphabetical list.

\section{Services}

The Services section of the Libraries' Web site lists links for multimedia support, making an appointment with a reference librarian, how to access library resources from off-campus, accessing course reserves, and logging in to your personal library account to check due dates or renew library materials.

Participants were very interested in having Course Reserves available on their mobile devices, especially if the content was only a few pages, indicating that they would be happy to read a brief item between classes or while killing time somewhere.

If I'm sitting around with my iPod or whatever and I have an hour between classes, and I've got something assigned on course reserves, I can sit down and read it. $(4 / 8 / 2009)$ 
I'd maybe use Course Reserves, just because professors they'll pull something that's pretty short like a couple of pages or so and I can flip through, read it on my phone instead of having to track down a computer. (4/20/2009)

With regard to their library account, participants expressed interest in being able to check the status of items they had checked out or requested as well as being able to place an item on hold or check its availability at the University Libraries.

I would definitely use My Library Account. I think for me that would be the most because I've always got overdue charges just because I don't get to a computer in time, but if you're able to access through your phone, that would be great. $(4 / 20 / 2009)$

\section{About Us}

Finally, we asked participants to rank the links on the About Us section of the libraries' Web site. The About Us section of the site features links we have seen on other library mobile Web sites, primarily hours of operation, locations and directions, and perhaps a staff directory. After reviewing examples of other mobile library Web sites, such as those from Duke or Ohio State, we anticipated that this section would be of most interest to library users.

From this set of links, participants were very interested in having a building guide and perhaps an explanation of the call number system available on a mobile device, especially because signage explaining the call numbers has gone unnoticed by participants:

It might be neat to have a link with something like help I can't find my book that would give you a rundown of how the call number works and where the book might be on the floor and what that little $Q$ in front means. Because I could see

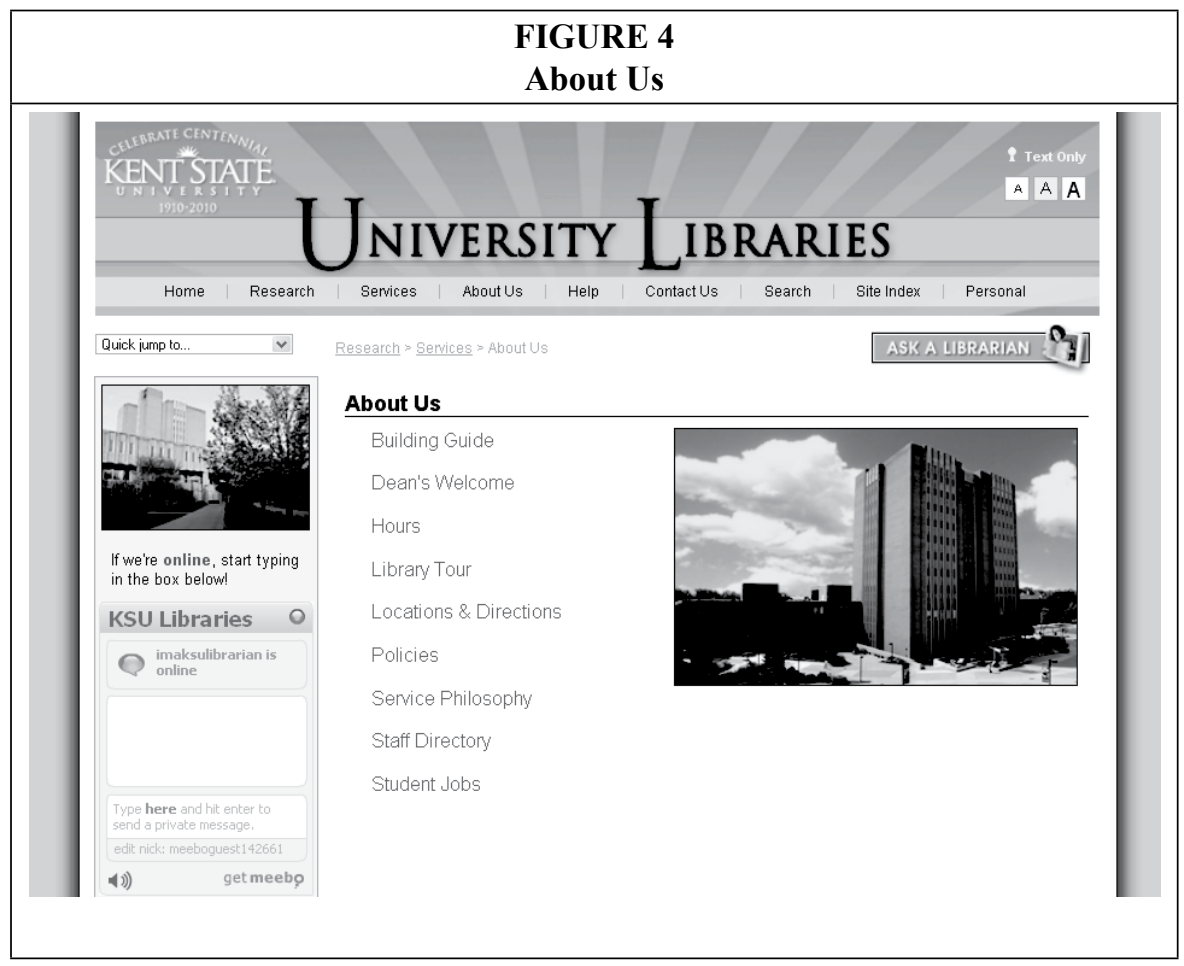


someone using that after a browse in the stacks to find a book and it's not where they want it to be. $(4 / 8 / 2009)$

While participants identified the building hours, directions and locations, a staff directory, and information about borrowing as their most important links from this area, overall this was not considered the most important section for inclusion on a mobile device.

\section{Overall}

Regardless of which section of the University Libraries' Web site being discussed in the focus group, participants identified the ability to contact a librarian as being of prime importance.

I kept circling the Contact Us on these sheets because there have been places that I've gone where you have to really hunt for any way to contact that site or the organization, so I think some way of contacting, whether it's through texting, you know, like they have up there, or something like that, there needs to be a contact link that's fairly prominent. $(4 / 20 / 2009)$

Whether through instant messaging or texting, participants were very interested in being able to contact a librarian for help via their mobile devices.

What if you could, like text or have a live chat with a librarian about a research question or how to cite something? That would be cool. $(3 / 4 / 2009)$

One participant summed up all the sessions:

I can imagine using the library site on my phone for two reasons. I think one would be just like vital info like are they open, where is it, just contact kind of information.....and then also just quick research, like I wouldn't sit down to write a term paper on my phone. (3/25/2009)

Overall, students ranked the Research section as their most important part of the current Web site. The Services section came in second and surprisingly, About Us was ranked last. This ranking stands in contrast to what has been considered the norm of the library mobile Web sites: keeping the content simple and basic. Other mobile versions of library Web sites prominently, or only, feature building hours, locations, and directions. The dynamics of a focus group may play a role in this ranking. In one session, links from the About Us section were ranked unanimously as the most important links for a mobile Web site; in another session, it was ranked third by a majority of the group. Regardless of individual sessions, these types of About Us links were deemphasized over links from the Research and Services section, which came as a surprise.

Students expressed a greater willingness to use their mobile devices to at least begin the research process, read course reserve materials, or look at their library accounts than we anticipated.

\section{Other Technologies}

The final question prompt asked participants to brainstorm other features they would like to see the library provide on mobile devices. Some common points emerged from this discussion, specifically the functionality of a mobile version of the library's catalog, customizable options, personalized information about their library accounts, and being able to text reference questions to a librarian.

Participants were interested in having access to the library's catalog on their mobile devices and had strong opinions about what other libraries have done in this area. During this portion of the focus group, we projected images from the mobile versions of library catalogs from Ohio State University and Texas Christian University. Participants were interested in being able to search the catalog on their 
mobile devices and request or place a book on hold from their phone. We were particularly interested in the participants' feedback with regard to the Ohio State University's mobile catalog, which uses the same integrated library system software as Kent State. Ohio State University's mobile version of their catalog runs off the Innovative Interfaces software for mobile devices, AirPac. Based on feedback from participants regarding the functionality of AirPac, we may delay purchasing the software to make our catalog fully searchable from a mobile device or explore customization options. Although participants liked the ability to request materials on their mobile device, the results lists did not offer enough information for each title to make it as useful on a mobile device as participants preferred. For a more detailed discussion of OPACs for mobile devices, see Samuel Liston's article in Computers in Libraries. ${ }^{15}$

Participants also wanted to see us develop customizable options and offer personalized information from the library regarding their library account and other services. With regard to their library accounts, participants in every focus group expressed a great deal of interest in being able to access their library accounts from their mobile devices and of being contacted via text messaging when a requested library item was available for pickup and when materials were nearing their due dates. Participants were also interested in receiving text message reminders about upcoming library appointments, such as scheduled meetings with a reference librarian, or updates via the libraries' assignment calendar about upcoming deadlines for projects.

\section{Emergent Themes}

In every focus group, we heard the same things: students were not only interested in getting basic information from a mobile Web site, they also desired greater interactivity with their mobile devices and envisioned being able to read, chat, and connect to resources. Participants saw themselves doing a variety of tasks on their mobile devices; they expressed a desire for a customizable experience and found design to be very important.

Participants envisioned themselves doing a variety of tasks on their mobile devices. The basics of the library Web site were considered important for a mobile Web version (hours, directions, locations), but participants desired more advanced items such as research databases and library catalogs. Even after the participants were cautioned that some sites such as research databases would not be formatted for mobile devices, they were still very interested in having the option to search and read from their mobile devices. It seems students are more adaptable to functioning on smaller screens than we think.

Being able to customize their mobile Web experience was another recurring theme across all sessions. Participants expressed interest in being able to pick their favorite databases or choose their own top ten links to see on a mobile Web site. This is a theme that seems to apply to a wide variety of experiences on the Web. Participants were very interested in being able to create unique, personalized experiences on the Web.

If you had the ability to make it so that you could customize it and maybe put like your favorite or most-used databases so you don't have to go all the way in to find the ones you want or use most often all the time, that would be a lot more convenient. (4/20/2009)

Another theme that emerged had to do with the design of mobile sites. Some participants expressed disappointment in the pared-down features of a mobile site, remarking that they did not feel they were on the Internet when accessing these bare-bones sites. Participants were looking for a more dynamic experience on mobile Web sites and were not very concerned with sites that were unformat- 
ted for mobile devices, as long as the sites loaded quickly.

I don't know much about designing mobile Web browsers but I feel like maybe it could look a little nicer or more professionally and still be pared down, just from a design perspective. (4/20/2009)

Ten or fewer links were considered the limit on links on a mobile Web site, and adequate spacing between links was identified as crucial, especially for mobile devices that use touchscreens. Participants also agreed that a link to the full university libraries site should be provided, regardless of its formatting, in case the user did not find what he or she needed on the mobile version.

\section{Further Research}

Research from the Pew Internet and American Life Study as well as the Nielsen Report discussed in the literature review provides information about who uses the mobile Web and how it is being used. The data from these nationwide reports are useful in gaining context for local library initiatives; however, localized data are necessary for developing Web content and tools to meet the needs of specific libraries with their unique populations. The data from our study, like all focus group studies, is limited in its ability to generalize the findings to a population outside Kent State University. The data we gathered from the focus group sessions were consistent; we will be using the results of this study when developing the Kent State University Libraries' mobile Web site. Considering some of the findings of this study, particularly the interest among Kent State students in doing research on their mobile devices, the current study highlights the individuality of academic institutions and suggests that other libraries should replicate the study at their own locations.

The results of our focus groups reinforce the need for seeking the input of students when planning new Web-based initiatives. Involving students in the design and testing of mobile initiatives will ensure that the design and functionality is meeting the needs of the potential users. Publishing the findings of such usability studies can be beneficial to other libraries in planning their own mobile design.

Further qualitative research needs to be conducted among university faculty, staff, and special populations of students such as distance learners and those with special needs. Web designers also need to be included in future research both to discuss feasibility of ideas and to gain their input about innovations in the field. Our study also did not look at how a mobile version of the libraries' Web site will be created and the obstacles that will be encountered in its creation. Further research will need to be conducted after the university libraries have a functioning mobile Web site to ascertain user satisfaction.

\section{Conclusion}

At the local level, a primary objective of this study was to gather feedback regarding user needs and expectations for the mobile libraries' Web site at Kent State. We were successful in setting limits on the amount of content that users would be interested in accessing on a mobile device. The general consensus was that the site should not be more than a few links deep and that each page should include no more than ten links. A link should be provided to the full site for users who do not have their needs met by the content selected for the mobile site. We were also successful in determining which links to provide through the discussion of the university libraries' traditional site.

Although it is certainly useful at the local level, the findings of the current study may be of use to other libraries planning a mobile Web version. Participants' interest in conducting research using their mobile device was certainly a surprise. Our assumption was that basic library information would suffice on a mobile Web site; however, the students 
who participated in this study wanted to be able to interact with library resources on their mobile devices. When planning a mobile Web version of their site, academic librarians may wish to gather data regarding user expectations, particularly their level of interest in using their mobile device. It may be necessary to offer more than contact information and hours on the mobile Web.

Finally, the current study highlights the need to take advantage of communication technologies beyond the mobile Web. Participants wanted to hear from the library via text messaging regarding their library accounts, research appointments, and assignment management. They also wanted to use communication technology to ask us questions. Participants listed the instant messaging reference service as a desired feature on a mobile Web site and wanted to be able to use text messaging to ask reference questions. Developing a mobile Web site that meets user needs and taking advantage of communication technology are two ways to allow students to fit the library into their increasingly busy and Web-connected lives.

\section{Notes}

1. "What Is the Mobile Web?" Library Technology Reports 44 (2008): 5-9.

2. Nielsen Mobile, "Critical Mass: The Worldwide State of the Mobile Web." Available online at www.nielsenmobile.com/documents/CriticalMass.pdf. [Accessed 24 September 2010].

3. John Horrigan, "The Mobile Difference." Pew Internet and American Life Project. Available online at www.pewinternet.org/Reports/2009/5-The-Mobile-Difference--Typology.aspx. [Accessed 24 September 2010].

4. Nielsen Mobile, "Critical Mass."

5. Horrigan, "The Mobile Difference."

6. Michael O'Leary, “Mobile Web: The New ‘Dial-Up,'” Online 24 (2000): 80-82.

7. Ellyssa Kroski, "Library Mobile Initiatives," Library Technology Reports 44 (2008): 33-38; Megan K. Fox, "Mobile Technologies in Libraries: How the Academic Library is Using PDA's, Handhelds, and Other Mobile Technologies," available online at http://web.simmons.edu/ fox/ pda [Accessed 24 September 2010]; Gerry McKiernan, "Mobile Libraries," available online at http://mobile-libraries.blogspot.com/ [Accessed 24 September 2010].

8. Fox, "Mobile Technologies in Libraries."

9. Library Success: A Best Practices Wiki. "M-Libraries." Available online at http://www. libsuccess.org/index.php?title=M-Libraries. [Accessed 24 September 2010].

10. Keren Mills, "M-Libraries: Information Use on the Move," report from Arcadia Programme (Cambridge, U.K.: University of Cambridge, 2009). Available online at http://arcadiaproject.lib. cam.ac.uk/docs/M-Libraries_report.pdf. [Accessed 24 September 2010].

11. Bill Mickey, "Mobile Audience Development," Circulation Management 23 (2008): 14-15; James A. Buczynski, "Libraries Begin to Engage Their Menacing Mobile Phone Hordes Without Shhhh!" Internet Reference Services Quarterly 13 (2008): 261-69.

12. Megan K. Fox, "Information Anywhere," Library Journal 133 (2008): 2-5; Joan K. Lippincott, "Mobile Technologies, Mobile Users: Implications for Academic Libraries," ARL 261 (2008): 1-4; Jim Hahn, "Mobile Learning for the Twenty-First Century Librarian," Reference Services Review 36 (2008): 272-88.

13. Joan K. Lippincott, "Libraries and Net Gen Learners: Current and Future Challenges in the Mobile Society," in M-Libraries: Libraries on the Move to Provide Virtual Access, Gill Needham and Mohamed Ally (London: Facet, 2008), 17-28..

14. Yang Cao, et al, "An Effective Mobile-Friendly Digital Library to Support Mobile Learners," in M-Libraries: Libraries on the Move to Provide Virtual Access, Gill Needham and Mohamed Ally (London: Facet, 2008), 109-22.

15. Samuel Liston, "OPACS and the Mobile Revolution," Computers in Libraries 29 (2009): 6-11, $42-47$. 